\title{
Article \\ Impact of a Digital Intervention for Literacy in Depression among Portuguese University Students: A Randomized Controlled Trial
}

\author{
Lersi D. Durán ${ }^{1, *(\mathbb{D}}$, Ana Margarida Almeida ${ }^{1}{ }^{1}$, Ana Cristina Lopes ${ }^{2}$ and Margarida Figueiredo-Braga ${ }^{3}(\mathbb{C}$ \\ 1 Department of Communication and Art, University of Aveiro/DigiMedia, 3810-193 Aveiro, Portugal; \\ marga@ua.pt \\ 2 Entre o Douro e Vouga Hospital Center, 4520-211 Santa Maria da Feira, Portugal; \\ anacristinalopes.sp@gmail.com \\ 3 Department of Clinical Neurosciences and Mental Health, School of Medicine, Porto University, \\ 4200-450 Porto, Portugal; mmfb@med.up.pt \\ * Correspondence: ldquintero@ua.pt
}

check for updates

Citation: Durán, L.D.; Almeida, A.M.; Lopes, A.C.; Figueiredo-Braga, M. Impact of a Digital Intervention for Literacy in Depression among Portuguese University Students: A Randomized Controlled Trial. Healthcare 2022, 10, 165. https:// doi.org/10.3390/healthcare10010165 Academic Editor: Abraham Rudnick Received: 15 December 2021 Accepted: 10 January 2022 Published: 15 January 2022

Publisher's Note: MDPI stays neutral with regard to jurisdictional claims in published maps and institutional affiliations.

Copyright: (C) 2022 by the authors. Licensee MDPI, Basel, Switzerland. This article is an open access article distributed under the terms and conditions of the Creative Commons Attribution (CC BY) license (https:// creativecommons.org/licenses/by/ $4.0 /)$.

\begin{abstract}
Digital interventions are important tools to promote mental health literacy among university students. "Depression in Portuguese University Students" (Depressão em Estudantes Universitários Portugueses, DEEP) is an audiovisual intervention describing how symptoms can be identified and what possible treatments can be applied. The aim of this study was to evaluate the impact of this intervention. A random sample of 98 students, aged 20-38 years old, participated in a 12-week study. Participants were recruited through social media by the academic services and institutional emails of two Portuguese universities. Participants were contacted and distributed into four study groups (G1, G2, G3 and G4): G1 received the DEEP intervention in audiovisual format; G2 was given the DEEP in text format; G3 received four news articles on depression; G4 was the control group. A questionnaire was shared to collect socio-demographic and depression knowledge data as a pre-intervention method; content was then distributed to each group following a set schedule; the depression knowledge questionnaire was then administered to compare pre-intervention, post-intervention and follow-up literacy levels. Using the Scheffé and Least Significant Difference (LSD) multiple comparisons test, it was found that G1, which received the DEEP audiovisual intervention, differed significantly from the other groups, with higher depression knowledge scores in post-intervention stages. The DEEP audiovisual intervention, compared to the other formats used (narrative text format; news format), proved to be an effective tool for increasing depression knowledge in university students.
\end{abstract}

Keywords: digital interventions; mental health literacy; audiovisual

\section{Introduction}

There are many digital resources that provide mental health information and support. Digital technology has become an addictive element used by young university students as a privileged tool to access information [1]. It is not surprising that young people seek support and information about mental health on the Internet [2-4]. However, much of the digital content on the Internet does not have scientific validity [5,6], which can become a problem due to the use of unreliable information.

Providing mental health knowledge and promoting health literacy to young university students is a challenge for universities and the public health system $[7,8]$. Nowadays, an increasing number of cases of young people with depression are undetected, unrecognized and undertreated, leading to tragic episodes such as suicide and causing a great impact on the family and social environment [9-11]. According to the World Health Organization, depression is the leading cause of disability worldwide [12]. University students are 
exposed to specific challenges given their new responsibilities and are reported as a risk population for mental health problems, namely anxiety and/or depression [13], which can trigger other, more serious, disorders [11]. Young people are often reluctant to seek professional help for a mental/psychological disorder [7,14], due to preconceived ideas imposed by society, low mental health literacy and fear of being exposed $[15,16]$.

Depression, according to Becken [17], is caused by a negative view of the world. A person with depressive symptoms has a negative cognition of the things around them. Depression is an illness in which feelings of deep sadness, emptiness, tiredness and lack of interest are present, which can lead to serious consequences such as suicide, causing great difficulties in family and social contexts [11].

Health literacy is of fundamental importance to guarantee a better quality of life on a personal and social level. This is a process that comprises three fundamental points, namely the capacity to analyze, understand and communicate $[16,18]$, and depends on the skills that the individual or society develops in order to obtain the expected results. The significance of mental health literacy highlights the need to increase knowledge of mental-psychological disorders, so that help and information are sought and stigma is reduced $[8,18]$.

In recent years, digital programs have been developed for the promotion, education and prevention of mental illnesses and/or disorders, with an emphasis on depression [18]. According to Frank, Pong, Asher and Soares [19], the use of digital programs may have positive effects on the understanding of depressive symptoms. The use of digital media to support interventions on depressive symptoms has been the subject of recent studies [20,21], which demonstrates the potential for using technology as a tool for the distribution of digital content in the area of depression [22]. Despite the wide variety of digital resources to treat and prevent depression, only a small number have been validated by specialists in the field $[6,23]$. For this reason, it is essential to develop further studies to validate the use of digital interventions on depression [24,25], and to better understand how the use of digital resources can provide well-being and mental health for university students.

Digital interventions can be used to provide a set of educational strategies with a cognitive orientation, allowing participants to learn about and/or face situations related to psychiatric disorders [26]. These interventions promote the integration of participants regardless of their geographical location $[26,27]$ and can therefore bring together a large number of people. This makes the learning and/or treatment process more productive, easier and more enjoyable [28]. Digital interventions aimed at mental health promotion and education address specific needs and have a high success rate in overcoming stigma [29]. Importantly, digital resources have great potential for health information provision [30]. Social support, lack of geographic boundaries, free access and ease of access are some of the advantages of digital resources for health promotion and literacy [19,31,32]. However, there are several concerns, such as disparities in Internet access, the quality of online health information and the lack of real support to monitor how this information is processed [1,29,33].

For Michie et al. [34], Hollis et al. [35] and Alkhaldi et al. [36], digital interventions for mental health promotion and care must pay close attention to the content and information to be presented [33,37]. These are special interventions that, because they deal with sensitive issues, must be supported and monitored by specialists to prevent them from being nonbeneficial resources for the participants [38]. Similarly, these digital resources for mental health promotion and literacy are based on pedagogical techniques, adapted to the needs of the participants. The information and content developed must have a technological, educational and explanatory context to ensure that the objective of a digital mental health literacy intervention is met [39].

The incorporation of an audiovisual format in the area of mental health literacy is considered an effective strategy to communicate, promote and support mental health literacy [40-42].

The evolution of technology and the digital world are part of the general population's life, especially among young people, thus allowing digital social media to be used as a 
tool to carry information in the area of mental health $[43,44]$. The concept of literacy that is associated with the ability to read and write thus expands and becomes the competence to promote or acquire information about, in this case within the scope of mental health $[20,45]$. The concept of literacy linked to technology is represented through images, sounds and videos, among other things [46]; therefore, the audiovisual format can be defined as a strategy to carry information in different forms of representation that generate interest in young audiences [47].

The digital audiovisual intervention DEEP consists of 23 short videos interspersed between a web series called "The Sara Wound" and informational videos about depression, divided into two stages. The first stage is "DEEP IN", which exposes the onset and acceptance of depressive symptoms, and the second stage "DEEP OUT", which presents the phase of seeking help and recovery.

This study aimed to evaluate the impact of the DEEP digital audiovisual intervention on Portuguese university students. The study considered their knowledge about the relevance they should give to symptoms and possible treatments, compared the audiovisual format of the intervention with the narrative text format and the news format and assessed the level of literacy before and after the intervention.

\section{Materials and Methods}

\subsection{Study Context and Ethical Considerations}

This study was conducted as part of the eMental project (evaluation of digital interventions for depression and suicide promotion and literacy), which aims to develop digital interventions for young university students and to understand the role they play in depression and suicide literacy. This research was developed as a randomized controlled trial, and the research protocol was approved by the Ethics Board of the University of Aveiro, Portugal (46-CED/2019).

\subsection{Study Design and Sample}

The evaluation of the impact of the intervention was conducted over a period of 14 weeks with an initial sample of 98 students, aged between 18 and 38 years old, of which $66 \%$ were female and $34 \%$ were male. The participants were students from two Portuguese universities and were randomly and equally divided into four groups, each group having access to information through different formats during the intervention. It should be noted that Group 1 received the DEEP intervention in audiovisual format and Group 4 was the control group. The purpose of having four groups was to allow comparison of the audiovisual format of DEEP intervention with the narrative text format of the same intervention, the narrative news format and to have a control group. It is important to note that only 71 students completed the first phase of the study.

Full access to the final version of this intervention cannot be presented in this paper as DEEP is still under analysis and development.

\subsection{Recruitment of Participants}

Students from two Portuguese universities were invited to participate in the study by means of an institutional email sent to all students, poster publications on the social networks of the universities' academic associations and printed posters placed in the common areas of the universities. The only criterion for participation was to be a university student, and the willingness to participate. No exclusion criteria were applied.

\subsection{Instruments}

After the recruitment campaign, those who were interested responded to the email quieroparticipar@ua.pt, sharing their intention to participate in the study. One week afterwards, participants were randomly divided into four groups. All groups were then sent a link via email to the initial questionnaire containing an introduction, an informed consent to participate form, a socio-demographic assessment (age and gender) and the 
pre-intervention knowledge literacy questionnaire. The literacy questionnaire was adapted from Griffiths et al. [15], Hart et al. [38] and Heickie et al. [48] and was tested in a pilot evaluation [25]. The questionnaire consists of true and false questions, divided into two parts: a first part of 25 questions on symptoms of depression, and a second part with 11 questions related to possible treatments. For the elaboration of the questionnaires and data collection, the software LimeSurvey was used on the platform https:/ / forms.ua.pt/ (accessed in 10 January 2022), from the University of Aveiro, Portugal.

Subsequently, content was sent via email to each group, ranging from DEEP intervention in the digital format for G1, to DEEP intervention in narrative text for G2, to four news items on depression for G3, and it followed a distribution schedule (Appendix A) for a period of 23 working days between 3 p.m. and 8 p.m. At the end of the distribution of content for each group, the literacy questionnaire was sent as a post-intervention measurement instrument.

The purpose of the literacy questionnaire was to characterize participants' knowledge about depression at pre-intervention, post-intervention and follow-up. Finally, and after receiving the follow-up responses, DEEP intervention was sent in audiovisual format to all groups, including the control group (G4). Figure 1 represents the timeline of the assessment design.

Distribution of the 4 groups

Sociodemographic data collection and pre-intervention evaluation (literacy questionnaire) follow-up evaluation (literacy questionnaire), send to all groups including G4 or control the DEEP intervention in audio-visual format. end of the intervention distribution of contents 23 days

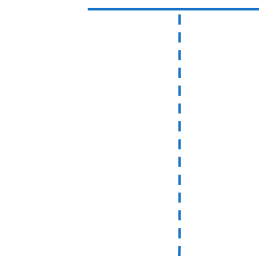

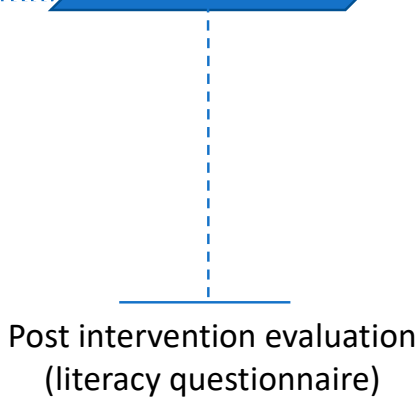

2 months

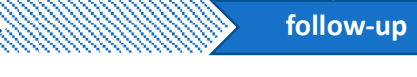

Figure 1. Timeline of the assessment design.

\subsection{Statistical Analysis}

For the quantitative data analysis, IBM ${ }^{\circledR}$ SPSS ${ }^{\circledR}$ software, version 24.0 for Windows ${ }^{\circledR}$, was used to compare the total scores of the four groups in the three evaluation phases (pre-, post-intervention and follow-up), using one-factor ANOVA. When it was verified that there was no normality in the sample, the Kruskal-Wallis test was used as a non-parametric alternative. Since significant differences were found, multiple comparison tests were carried out using the Scheffé and Least Significant Difference (LSD) tests as they are adjusted when there is no normality and homogeneity of variances. For all cases, a level of $5 \%$ was used for the statistically significant value $(p<0.05)$. 


\section{Results}

The results of the socio-demographic data are shown in Table 1. Considering the 71 university students who completed the entire literacy questionnaire and the sociodemographic data questionnaire in the pre-intervention phase, the age range was from 18 to 38 years old, the largest number of participants were female, and for the marital status of the participants, 60 out of the 71 were single. Regarding the place where they lived during the class period, 51 had to move from the family residence into a university residence due to the geographical distance between their home residences and the university.

Table 1. Socio-demographic characteristics of participants $(n=71)$.

\begin{tabular}{|c|c|c|c|c|c|c|c|}
\hline \multirow{2}{*}{$\begin{array}{c}\qquad n=71 \\
\text { Age Range }\end{array}$} & \multicolumn{2}{|c|}{ Gender } & \multicolumn{3}{|c|}{ Marital Status } & \multicolumn{2}{|c|}{$\begin{array}{c}\text { Place of Residence during the Period of } \\
\text { University Classes }\end{array}$} \\
\hline & Male & Female & Single & Married & Partnership & $\begin{array}{c}\text { Student } \\
\text { Residence }\end{array}$ & $\begin{array}{l}\text { At Home with } \\
\text { Their Family }\end{array}$ \\
\hline 20 and 38 years old & 24 & 47 & 60 & 9 & 2 & 51 & 20 \\
\hline
\end{tabular}

It is important to note that the initial sample decreased when comparing each of the phases (pre-, post- and follow-up) of the intervention. Only 36 students reached the end of the study, a drop-out rate of $63.36 \%$. Table 2 shows the number of students per group throughout the study and the results per group of the two literacy questionnaire sections.

Table 2. Results per literacy questionnaire group: number of participants, significant differences, and means in each phase of the study.

\begin{tabular}{|c|c|c|c|c|c|c|c|c|c|c|c|c|}
\hline \multirow{3}{*}{$\begin{array}{l}\text { Study } \\
\text { Group }\end{array}$} & \multicolumn{4}{|c|}{ Pre-Intervention $(n=71)$} & \multicolumn{4}{|c|}{ Post-Intervention $(n=56)$} & \multicolumn{4}{|c|}{ Follow-Up $(n=36)$} \\
\hline & \multicolumn{2}{|c|}{ Section 1} & \multicolumn{2}{|c|}{ Section 2} & \multicolumn{2}{|c|}{ Section 1} & \multicolumn{2}{|c|}{ Section 2} & \multicolumn{2}{|c|}{ Section 1} & \multicolumn{2}{|c|}{ Section 2} \\
\hline & Mean & $\begin{array}{c}p \\
\text { Value }\end{array}$ & Mean & $\begin{array}{c}p \\
\text { Value }\end{array}$ & Mean & $\begin{array}{c}p \\
\text { Value }\end{array}$ & Mean & $\begin{array}{c}p \\
\text { Value }\end{array}$ & Mean & $\begin{array}{c}p \\
\text { Value }\end{array}$ & Mean & $\begin{array}{c}p \\
\text { Value }\end{array}$ \\
\hline G1 & 20.85 & 0.056 & 7.55 & 0.35 & 22.19 & $0.019 *$ & 8.88 & $0.015 *$ & 20.53 & 0.095 & 8.90 & 0.092 \\
\hline G2 & 20.82 & 0.107 & 6.71 & 0.451 & 21.36 & 0.175 & 7.14 & 0.118 & 20.11 & 0.264 & 7.00 & 0.242 \\
\hline G3 & 21.81 & 0.054 & 7.41 & 0.262 & 19.33 & 0.045 & 7.33 & 0.092 & 18.40 & 0.043 & 5.50 & 0.468 \\
\hline G4 & 20.41 & 0.118 & 7.71 & 0.094 & 20.42 & 0.091 & 7.50 & 0.059 & 20.80 & 0.191 & 7.60 & 0.445 \\
\hline
\end{tabular}

* The mean difference is significant at the 0.05 level.

To measure the knowledge of respondents in the three phases of the intervention (pre-, post- and follow-up), the literacy questionnaire was used, divided into two sections: "Symptom identification" (Section 1) and "Possible treatments" (Section 2). For each section, the number of correct answers was added together, resulting in a final score. Therefore, the scores for Section 1 ranged from 0 to 25, and for Section 2, the scores ranged from 0 to 11.

It was necessary to test the normality of G1 data in the post-intervention phase, and no statistical significance was obtained. Hence, the assumption that G1 follows a normal distribution was rejected, and therefore, a non-parametric Kruskal-Wallis test was performed to measure if there were significant differences and to determine if the level of knowledge was equal or not in all phases.

In Table 3, the results of the Kruskal-Wallis test can be observed. For Sections 1 and 2 of G1, it can be seen that the significant group differences for each section are under $5 \%$, thus rejecting the hypothesis that knowledge about depression is the same in all three phases.

After rejecting the hypothesis of equality, it was important to know which phase was responsible for this difference by creating a score-ordering variable for multiple comparisons between phases, using the Scheffé test for Section 1 and the LSD (least significant difference) test for Section 2. 
Table 3. Kruskal-Wallis test results.

\begin{tabular}{ccc}
\hline \multirow{2}{*}{ Teste } & \multicolumn{2}{c}{ G1 } \\
\cline { 2 - 3 } & Section 1 & Section 2 \\
\hline Kruskal-Wallis H & 12.367 & 7.126 \\
$p$ value & $0.028^{*}$ & $0.02 *$ \\
\hline
\end{tabular}

* The mean difference is significant at the 0.05 level.

The results of these multiple comparison statistical tests are in Table 4. The significant differences are marked with an asterisk, where it can be observed that G1 in the follow-up phase showed higher literacy levels compared to the pre-intervention phase. In Sections 1 and 2 in the pre-intervention phase, G1 had lower literacy levels than in the post-intervention and follow-up phases.

Table 4. Results of multiple comparison tests between phases of G1.

\begin{tabular}{|c|c|c|c|c|c|c|c|}
\hline \multirow[t]{2}{*}{ Group G1 } & \multirow[t]{2}{*}{ Group G1 } & \multicolumn{3}{|c|}{ Sheffeé Test } & \multicolumn{3}{|c|}{ LSD test } \\
\hline & & \multicolumn{3}{|c|}{ Section 1} & \multicolumn{3}{|c|}{ Section 2} \\
\hline Phase (I) & Phase (J) & $\begin{array}{c}\text { Mean Difference } \\
(\mathrm{I}-\mathrm{J})\end{array}$ & Std. Error & Sig. & $\begin{array}{c}\text { Mean Difference } \\
(\mathrm{I}-\mathrm{J})\end{array}$ & Std. Error & Sig. \\
\hline \multirow[b]{2}{*}{ Pre-intervention } & Post-intervention & -9.506250 & 3.872342 & 0.060 & $-10.275000^{*}$ & 4.140478 & 0.017 \\
\hline & Follow-up & -17.450000 & 4.471395 & 0.001 & $-10.700000 *$ & 4.781013 & 0.030 \\
\hline \multirow{2}{*}{$\begin{array}{c}\text { Post- } \\
\text { intervention }\end{array}$} & Pre-intervention & 9.506250 & 3.872342 & 0.060 & 10.275000 * & 4.140478 & 0.017 \\
\hline & Follow-up & -7.943750 & 4.653976 & 0.244 & -0.425000 & 4.976236 & 0.932 \\
\hline \multirow{2}{*}{ Follow-up } & Pre-intervention & 17.450000 * & 4.471395 & 0.001 & 10.700000 * & 4.781013 & 0.030 \\
\hline & Post-intervention & 7.943750 & 4.653976 & 0.244 & 0.425000 & 4.976236 & 0.932 \\
\hline
\end{tabular}

* The mean difference is significant at the 0.05 level.

\section{Discussion}

This study evaluated the impact of the DEEP audiovisual intervention on university students. When comparing the results obtained in the pre- and post-intervention phases, it becomes clear that the mean number of correct answers in both sections only increased in groups G1 and G2. Significant differences $(p>0.05)$ were only obtained in G1. Therefore, depression literacy levels were significantly higher in this group, which demonstrates that digital content has a high potential to provide mental health literacy $[25,26,33,39,40,49]$.

It is noteworthy that the knowledge of G3, who received information about depression in narrative notecard format, decreased, and that G4, or the control group, maintained the same knowledge in these phases. These results may suggest that young university students find it easier to obtain information through digital content because of the importance they place on the use of technology. At the same time, based on study findings, it may be inferred that the use of other formats may discourage young university students from acquiring new knowledge $[2,8,9,13]$.

According to Carbonell et al. [1], Horgan and Sweeney [2], Griffiths et al. [15] and Uddin et al. [30], university students are immersed in the world of digital technology, so they are more interested in obtaining information and knowledge when the content is digital, which was corroborated by this study's findings, since it was shown that the format used for G3 and G4 was not as captivating as the digital format to generate interest in learning. However, for the follow-up phase, 2 months afterward, the scores did not increase. Despite this, the G1 and G2 groups maintained a level of knowledge very close to that of the pre-intervention phase. Although a decrease in knowledge of digital literacy interventions over time has been described in the literature $[21,47,50]$, the DEEP intervention managed to maintain relatively unchanged knowledge levels of depression in the participants in the follow-up phase. It is important to further explore the impact of these results and the factors that influenced them by conducting an evaluation with more students and analyzing the different scenarios for each group. 
The G4 or control group increased knowledge between the post-intervention and follow-up phases, but this increase was not statistically significant. This could confirm that when there is the presence of a control group, these groups feel the need to seek information on the topic because they are not involved in the interventions.

This work has several limitations, which must be acknowledged.

One limitation was the recruitment of participants to the study. Despite the strategies used, it was difficult to motivate students to agree to participate. Another possible limitation may have been the use of a questionnaire as a measurement instrument. Although this methodological choice was made in order to measure knowledge during all stages of the intervention, it may have contributed to participants dropping out of the intervention, since many students did not complete the questionnaire in the post-intervention and follow-up phases and therefore gave up continuing in the study. Studies with more than two followup phases generally have a high drop-out rate, especially if the participants do not receive a reward that interests them $[9,11]$. In this study, the drop-out rate was high, representing $63 \%$ of the initial sample. In this case, the representativeness of the sample is not fully accomplished, since the final results obtained cannot be generalizable.

However, the drop-out rate during the study did not impede the study, nor did it affect the results, as all four groups maintained an equivalent number of students. Although it is not possible to generalize the conclusions, the results found presuppose an initial step for future studies, in which a strategy should be considered to keep participants enrolled in the study for the duration of the intervention and thus reduce the drop-out rate.

Another limitation of this study was the fact that we could not $100 \%$ control the risk of contamination between groups. The choice of participants per group was random; we did not know and could not identify the participants due to the General Data Protection Regulation (GDPR). Alternatives to control the groups were not possible to implement because they would identify the participants; we only checked G1 for the number of views of each video during the time of the intervention.

It could also be considered a limitation of this work that G3 received only four news articles about depression in digital format during the intervention. In fact, this group differed both in content and format from the other groups, but this strategy was used to try to compare the audiovisual format of the digital intervention with the remaining formats, and thus find out if the DEEP intervention in audiovisual format would have more influence on participants' knowledge of depression.

Youth mental health literacy should be an area of further exploration, so that young people can recognize and respond appropriately to the signs and symptoms of depression or other mental disorders [3,4,9]. Future studies should focus on developing effective technology-linked interventions to improve knowledge and thus raise awareness among young university students about how to care for and maintain good mental health.

\section{Conclusions}

The DEEP digital intervention is based on an audiovisual strategy, grounded in a clinical-social approach, with the aim of improving the depression knowledge of Portuguese university students and with the intention of increasing quality of life and creating a state of full well-being.

The results of this study provide evidence that digital audiovisual content is more likely to increase depression literacy in university students than other formats. Young people learned more from the audiovisual content of the DEEP intervention than students who received the other formats with equivalent information. It is necessary that these interventions are evaluated by specialists before being delivered to the participants, because, as they deal with sensitive topics, information may be shared that is harmful to the participants.

Evaluating the DEEP intervention enriched the perception of the role of digital technologies to promote literacy in depression, highlighting the importance of complementing interventions with two different approaches: information videos (as a substitute for a 
specialist in the area) interspersed with videos of Sara's story (portraying the reality of a university student).

Digital technology and mental health together form a key partnership to address current public health challenges and are allies in improving the quality of mental health among university students, which is currently even more fragile due to the pandemic scenario. The DEEP digital intervention format highlighted the potential for videos as a vehicle to increase depression literacy, enabling the understanding of the disease, considering symptom identification and possible treatments. It is also important to note that digital interventions can be scaled up to all audiences and thus provide better health care whether for promotion/literacy/therapy or treatment of mental disorders.

Author Contributions: Methodology, L.D.D. and A.M.A.; validation, A.M.A. and A.C.L.; formal analysis, L.D.D.; investigation, L.D.D.; resources, A.M.A. and M.F.-B.; data curation, L.D.D.; writingoriginal draft preparation, L.D.D.; writing-review and editing, A.M.A., A.C.L. and M.F.-B.; visualization, A.M.A., A.C.L. and M.F.-B.; supervision, A.M.A. and M.F.-B.; project administration, A.M.A.; funding acquisition, L.D.D. All authors have read and agreed to the published version of the manuscript.

Funding: This paper is funded by the project eMental (ref 45-2019/393, funded by Ciência Viva) and the research grant reference B/UI73/8905/2021. Thanks are due to FCT/MCTES for the financial support to DigiMedia (UIDP/05460/2020 + UIBD/05460/2020), through national funds.

Institutional Review Board Statement: The study was conducted according to the guidelines of the Declaration of Helsinki, and approved by the Ethics Board of the University of Aveiro, Portugal (46-CED/2019 and date of approval: 1 April 2020).

Informed Consent Statement: Informed consent was obtained from all subjects involved in the study.

Data Availability Statement: The data that support the findings of this study are available from the corresponding author and the team involved in the project. Data are however available with upon reasonable request and with permission and autorizated the team.

Acknowledgments: To Ciência Viva, for the financial support of eMental Project "Assessing digital interventions for the promotion of literacy in depression and suicide". to Digital Media and Interaction research centre (DigiMedia) of the University of Aveiro and to the students involved in the development of the audiovisual intervention DEEP.

Conflicts of Interest: The authors declare that they have no conflict of interests.

\section{Appendix A}

This section presents the timetable used for sending the contents to each group. The sending occurred via email, and in Table A1, the days on which the groups received the contents are highlighted in bold.

Table A1. Calendar with the days when the contents were sent.

\begin{tabular}{ccccc}
\hline Mon & Tue & Wed & Thu & Fri \\
\hline Day 1 & Day 2 & Day 3 & Day 4 & Day 5 \\
Day 6 & Day 7 & Day 8 & Day 9 & Day 10 \\
Day 11 & Day 12 & Day 13 & Day 14 & Day 15 \\
Day 16 & Day 17 & Day 18 & Day 19 & Day 20 \\
Day 21 & Day 22 & Day 23 & Day24 & Day 25 \\
Day 26 & Day 27 & Day 28 & Day 29 & Day 30 \\
Day 31 & Day 32 & Day 33 & Day 34 & Day 35 \\
Day 36 & Day 37 & Day 38 & Day 39 & Day 40 \\
\hline
\end{tabular}

Table A2 shows the day, time and content sent to each group. The time varies between 4:00 p.m. and 7:00 p.m., generating a surprise factor when each content was sent. 
Table A2. Timetable and contents sent to each group.

\begin{tabular}{|c|c|c|c|c|}
\hline \multicolumn{5}{|c|}{ Content Distribution Schedule } \\
\hline Day & Hour & Content Group 1 & Content Group 2 & Content Group 3 \\
\hline Day 1 & $16: 00$ & Teaser/PE-Video 1 & Teaser/PE-Video 1 & Article 1 \\
\hline Day 2 & 18:00 & FS Video 1 & FS text 1 & \\
\hline Day 5 & 19:00 & PE Video 2 & PE text 2 & \\
\hline Day 7 & $17: 00$ & FS Video 2 & FS text 2 & \\
\hline Day 9 & $16: 00$ & PE Video 3 & PE text 3 & \\
\hline Day10 & $18: 00$ & FS Video 3 & FS text 3 & \\
\hline Day 11 & 19:00 & PE Video 4 & PE text 4 & \\
\hline Day 13 & $18: 00$ & FS Video 4 & FS text 4 & Article 2 \\
\hline Day 14 & 19:00 & PE Video 5 & PE tex 5 & \\
\hline Day 17 & $16: 00$ & FS Video 5 & FS text 5 & \\
\hline Day 20 & 19:00 & PE Video 6 & PE text 6 & \\
\hline Day 21 & $17: 00$ & FS Video 6 & FS text 6 & \\
\hline Day 23 & $16: 00$ & FS Video 7 & FS text 7 & \\
\hline Day 24 & $18: 00$ & PE Video 7 & PE text 7 & Article 3 \\
\hline Day 27 & $17: 00$ & FS Video 8 & FS text 8 & \\
\hline Day 28 & $19: 00$ & PE Video 8 & PE text 8 & \\
\hline Day 30 & $16: 00$ & FS Video 9 & FS text 9 & \\
\hline Day 31 & $19: 00$ & PE Video 9 & PE text 9 & \\
\hline Day 34 & $17: 00$ & FS Video 10 & FS text 10 & \\
\hline Day 35 & $18: 00$ & FS Video 11 & FS text 11 & \\
\hline Day 37 & $16: 00$ & FS Video 12 & FS text 12 & Article 4 \\
\hline Day 38 & 19:00 & PE Video 10 & PE text 10 & \\
\hline Day 40 & $17: 00$ & FS Video 13 & FS text 13 & \\
\hline
\end{tabular}

FS video X: video of "the wound Sara", episode X; PE video X: psychoeducational video, episode X; FS text X narrative text of "the wound Sara", episode X; PE text X: psychoeducational narrative texts; article X: news article from some Portuguese newspapers.

\section{References}

1. Carbonell, X.; Chamarro, A.; Oberst, U.; Rodrigo, B.; Prades, M. Problematic Use of the Internet and Smartphones in University Students: 2006-2017. Int. J. Environ. Res. Public Health 2018, 15, 475. [CrossRef]

2. Horgan, Á.; Sweeney, J. Young Students' Use of the Internet for Mental Health Information and Support. J. Psychiatr. Ment. Health Nurs. 2010, 17, 117-123. [CrossRef]

3. Burns, J.M.; Davenport, T.A.; Durkin, L.A.; Luscombe, G.M.; Hickie, I.B. The Internet as a Setting for Mental Health Service Utilisation by Young People. Med. J. Aust. 2010, 192 (Suppl. 11), S22-S26. [CrossRef]

4. Chen, W.; Zheng, Q.; Liang, C.; Xie, Y.; Gu, D. Factors Influencing College Students' Mental Health Promotion: The Mediating Effect of Online Mental Health Information Seeking. Int. J. Environ. Res. Public Health 2020, 17, 4783. [CrossRef]

5. Christensen, H.; Griffiths, K. The Internet and Mental Health Literacy. Aust. N. Z. J. Psychiatry 2016, 34, 975-979. [CrossRef] [PubMed]

6. Mathews, S.C.; McShea, M.J.; Hanley, C.L.; Ravitz, A.; Labrique, A.B.; Cohen, A.B. Digital Health: A Path to Validation. NPJ Digit. Med. 2019, 2, 38. [CrossRef] [PubMed]

7. Cova Solar, F.; Alvial, S.W.; Aro, D.M.; Bonifetti, D.A.; Hernández, M.M.; Rodríguez, C.C. Problemas de Salud Mental En Estudiantes de La Universidad de Concepción. Ter. Psicológica 2007, 25, 105-112. [CrossRef]

8. Oliveira, C.; Varela, A.; Esteves, J.; Henriques, C.; Ribeiro, A. Programas De Prevenção Para a Ansiedade E Depressão: Avaliação Da Percepção Dos Estudantes Universitários. Programas Prevenção Para A Ansiedade E Depress 2016, 111, 96-111.

9. Frazier, P.; Meredith, L.; Greer, C.; Paulsen, J.A.; Howard, K.; Dietz, L.R.; Qin, K. Randomized Controlled Trial Evaluating the Effectiveness of a Web-Based Stress Management Program among Community College Students. Anxiety Stress Coping 2014, 28, 576-586. [CrossRef]

10. Hoare, E.; Collins, S.; Marx, W.; Callaly, E.; Moxham-Smith, R.; Cuijpers, P.; Holte, A.; Nierenberg, A.A.; Reavley, N.; Christensen, H.; et al. Universal Depression Prevention: An Umbrella Review of Meta-Analyses. J. Psychiatr. Res. 2021, 144, 483-493. [CrossRef]

11. Wongpakaran, N.; Oon-Arom, A.; Karawekpanyawong, N.; Lohanan, T.; Leesawat, T.; Wongpakaran, T. Borderline Personality Symptoms: What Not to Be Overlooked When Approaching Suicidal Ideation among University Students. Healthc 2021, 9, 1399. [CrossRef] [PubMed]

12. WHO. Depression. WHO, 2017. Available online: http://www.who.int/mental_health/management/depression/en/ (accessed on 16 June 2020). 
13. Zhou, L.; Parmanto, B. Development and Validation of a Comprehensive Well-Being Scale for People in the University Environment (Pitt Wellness Scale) Using a Crowdsourcing Approach: Cross-Sectional Study. J. Med. Internet Res. 2020, 22, e15075. [CrossRef] [PubMed]

14. Pretorius, C.; Chambers, D.; Coyle, D. Young People's Online Help-Seeking and Mental Health Difficulties: Systematic Narrative Review. J. Med. Internet Res. 2019, 21, e13873. [CrossRef]

15. Griffiths, K.M.; Christensen, H.; Jorm, A.F.; Evans, K.; Groves, C. Effect of Web-Based Depression Literacy and CognitiveBehavioural Therapy Interventions on Stigmatising Attitudes to Depression. Br. J. Psychiatry 2004, 185, 342-349. [CrossRef]

16. Warchoł, T. Przegląd Badań Edukacyjnych Educational Studies Review Tomasz Warchoł A Sense of the Role and Value of Non-Formal Education in the Opinion of Students Participating in Interactive Workshops. Przegląd Badań Eduk. Educ. Stud. Rev. 2018, 2, 71-84. [CrossRef]

17. Beck, A.; Rush, A.; Shaw, B.; Emery, G. Cognitive Therapy of Depression. Aust. N. Z. J. Psychiatry 1979, 36, 272-275. [CrossRef]

18. Garrido, S.; Millington, C.; Cheers, D.; Boydell, K.; Schubert, E.; Meade, T.; Nguyen, Q.V. What Works and What Doesn't Work? A Systematic Review of Digital Mental Health Interventions for Depression and Anxiety in Young People. Front. Psychiatry 2019, 10, 759. [CrossRef] [PubMed]

19. Frank, E.; Pong, J.; Asher, Y.; Soares, C.N. Smart Phone Technologies and Ecological Momentary Data: Is This the Way Forward on Depression Management and Research? Curr. Opin. Psychiatry 2018, 31, 3-6. [CrossRef]

20. Peng, Z.; Hu, Q.; Dang, J. Multi-Kernel SVM Based Depression Recognition Using Social Media Data. Int. J. Mach. Learn. Cybern. 2019, 10, 43-57. [CrossRef]

21. Wei, Y.; McGrath, P.J.; Hayden, J.; Kutcher, S. Mental Health Literacy Measures Evaluating Knowledge, Attitudes and HelpSeeking: A Scoping Review. BMC Psychiatry 2015, 15, 291. [CrossRef]

22. Giosan, C.; Mogoaşe, C.; Cobeanu, O.; Szentágotai Tătar, A.; Mureşan, V.; Boian, R. Using a Smartphone App to Reduce Cognitive Vulnerability and Mild Depressive Symptoms: Study Protocol of an Exploratory Randomized Controlled Trial. Trials 2016, 17, 609. [CrossRef]

23. Mohr, D.C.; Tomasino, K.N.; Lattie, E.G.; Palac, H.L.; Kwasny, M.J.; Weingardt, K.; Karr, C.J.; Kaiser, S.M.; Rossom, R.C.; Bardsley, L.R.; et al. IntelliCare: An Eclectic, Skills-Based App Suite for the Treatment of Depression and Anxiety. J. Med. Internet Res. 2017, 19, e10. [CrossRef] [PubMed]

24. Almeida, A.M.P.; Almeida, H.S.; Figueiredo-Braga, M. Mobile Solutions in Depression: Enhancing Communication with Patients Using an SMS-Based Intervention. Procedia Comput. Sci. 2018, 138, 89-96. [CrossRef]

25. Kerst, A.; Zielasek, J.; Gaebel, W. Smartphone Applications for Depression: A Systematic Literature Review and a Survey of Health Care Professionals' Attitudes towards Their Use in Clinical Practice. Eur. Arch. Psychiatry Clin. Neurosci. 2019, 270, 139-152. [CrossRef] [PubMed]

26. Durán, L.; Almeida, A.M.; Figueiredo-Braga, M. Digital Audiovisual Contents for Literacy in Depression: A Pilot Study with University Students. Procedia Comput. Sci. 2021, 181, 239-246. [CrossRef]

27. Sin, J.; Gillard, S.; Spain, D.; Cornelius, V.; Chen, T.; Henderson, C. Effectiveness of Psychoeducational Interventions for Family Carers of People with Psychosis: A Systematic Review and Meta-Analysis. Clin. Psychol. Rev. 2017, 56, 13-24. [CrossRef]

28. Khan, I.; Melro, A.; Oliveira, L.; Amaro, A.C. Internet of Things Prototyping for Cultural Heritage Dissemination. J. Digit. Media Interact. 2020, 3, 20-35.

29. Grigsby, T.J.; Unger, J.B.; Molina, G.B.; Baron, M. Evaluation of an Audio-Visual Novela to Improve Beliefs, Attitudes and Knowledge toward Dementia: A Mixed-Methods Approach. Clin. Gerontol. 2017, 40, 130-138. [CrossRef]

30. Uddin, S.; Al Mamun, A.; Iqbal, M.A.; Nasrullah, M. Internet Addiction Disorder and Its Pathogenicity to Psychological Distress and Depression among University Students: A Cross-Sectional Pilot Study in Bangladesh. Psychology 2016, 7, $1126-1137$. [CrossRef]

31. Chu, J.T.; Wang, M.P.; Shen, C.; Viswanath, K.; Lam, T.H.; Chan, S.S.C. How, When and Why People Seek Health Information Online: Qualitative Study in Hong Kong. Interact. J. Med. Res. 2017, 6, e24. [CrossRef] [PubMed]

32. Pinto, L.T.; Figueiredo, V.A. Redes Sociais: Oportunidade de Buscar Evidências Nas Informações Compartilhadas Pelos Alunos. Rev. Inf. Educ. 2020, 1, 1-8.

33. Thornicroft, G.; Mehta, N.; Clement, S.; Evans-Lacko, S.; Doherty, M.; Rose, D.; Koschorke, M.; Shidhaye, R.; O'Reilly, C.; Henderson, C. Evidence for Effective Interventions to Reduce Mental-Health-Related Stigma and Discrimination. Lancet 2016, 387, 1123-1132. [CrossRef]

34. Michie, S.; Yardley, L.; West, R.; Patrick, K.; Greaves, F. Developing and Evaluating Digital Interventions to Promote Behavior Change in Health and Health Care: Recommendations Resulting from an International Workshop. Journal of Medical Internet Research. J. Med. Internet Res. 2017, 19, e232. [CrossRef]

35. Hollis, C.; Sampson, S.; Simons, L.; Davies, E.B.; Churchill, R.; Betton, V.; Butler, D.; Chapman, K.; Easton, K.; Gronlund, T.A.; et al. Identifying Research Priorities for Digital Technology in Mental Health Care: Results of the James Lind Alliance Priority Setting Partnership. Lancet Psychiatry 2018, 5, 845-854. [CrossRef]

36. Alkhaldi, G.; Hamilton, F.L.; Lau, R.; Webster, R.; Michie, S.; Murray, E. The Effectiveness of Prompts to Promote Engagement with Digital Interventions: A Systematic Review. J. Med. Internet Res. 2016, 18, e6. [CrossRef] 
37. Duran, L.Q.; Almeida, A.M.P.; Figueiredo-Braga, M. Digital Audiovisual Narratives as Depression Literacy Promoters: Development of Psychoeducational Intervention DEEP. In Proceedings of the 15th Iberian Conference on Information Systems and Technologies (CISTI), Sevilla, Spain, 24-27 June 2020; pp. 1-6. [CrossRef]

38. Patel, S.; Akhtar, A.; Malins, S.; Wright, N.; Rowley, E.; Young, E.; Sampson, S.; Morriss, R. The Acceptability and Usability of Digital Health Interventions for Adults with Depression, Anxiety, and Somatoform Disorders: Qualitative Systematic Review and Meta-Synthesis. J. Med. Internet Res. 2020, 22, e16228. [CrossRef]

39. Hart, S.R.; Kastelic, E.A.; Wilcox, H.C.; Beaudry, M.B.; Musci, R.J.; Heley, K.M.; Ruble, A.E.; Swartz, K.L. Achieving Depression Literacy: The Adolescent Depression Knowledge Questionnaire (ADKQ). Sch. Ment. Health 2014, 6, 213-223. [CrossRef] [PubMed]

40. Spiker, D.A.; Hammer, J.H. Mental Health Literacy as Theory: Current Challenges and Future Directions. J. Ment. Health 2019, 28, 238-242. [CrossRef] [PubMed]

41. Farrer, L.; Gulliver, A.; Chan, J.K.Y.; Batterham, P.J.; Reynolds, J.; Calear, A.; Tait, R.; Bennett, K.; Griffiths, K.M. Technology-Based Interventions for Mental Health in Tertiary Students: Systematic Review. J. Med. Internet Res. 2013, 15, e101. [CrossRef]

42. Bona, R.J. Audiovisual Narratives Aimed at Children's Audience in the Early 1990s: Transmedia Intertextuality Practices in Cartoons. Estud. em Comun. 2018, 1, 215-229. [CrossRef]

43. Dowling, D.O.; Miller, K.J. Immersive Audio Storytelling: Podcasting and Serial Documentary in the Digital Publishing Industry. J. Radio Audio Media 2019, 26, 167-184. [CrossRef]

44. Naslund, J.A.; Bondre, A.; Torous, J.; Aschbrenner, K.A. Social Media and Mental Health: Benefits, Risks, and Opportunities for Research and Practice. J. Technol. Behav. Sci. 2020, 5, 245-257. [CrossRef]

45. Glick, G.; Druss, B.; Pina, J.; Lally, C.; Conde, M. Use of Mobile Technology in a Community Mental Health Setting. J. Telemed. Telecare 2015, 22, 430-435. [CrossRef]

46. Kutcher, S.; Bagnell, A.; Wei, Y. Mental Health Literacy in Secondary Schools: A Canadian Approach. Child Adolesc. Psychiatr. Clin. 2015, 24, 233-244. [CrossRef]

47. Ito-Jaeger, S.; Vallejos, E.P.; Curran, T.; Spors, V.; Long, Y.; Liguori, A.; Warwick, M.; Wilson, M.; Crawford, P. Digital Video Interventions and Mental Health Literacy among Young People: A Scoping Review. J. Ment. Health 2021, 1-11. [CrossRef] [PubMed]

48. Hickie AM, I.B.; Davenport, T.A.; Luscombe, G.M.; Rong, Y.; Hickie, M.L.; Bell, M.I. The Assessment of Depression Awareness and Help-Seeking Behaviour: Experiences with the International Depression Literacy Survey. BMC Psychiatry 2007, 7, 48. [CrossRef]

49. Janoušková, M.; Tušková, E.; Weissová, A.; Trančík, P.; Pasz, J.; Evans-Lacko, S.; Winkler, P. Can Video Interventions Be Used to Effectively Destigmatize Mental Illness among Young People? A Systematic Review. Eur. Psychiatry 2017, 41, 1-9. [CrossRef]

50. Seedaket, S.; Turnbull, N.; Phajan, T.; Wanchai, A. Improving Mental Health Literacy in Adolescents: Systematic Review of Supporting Intervention Studies. Trop. Med. Int. Health 2020, 25, 1055-1064. [CrossRef] 